Patronos, jerarcas y franquistas. Actitudes y recursos coercitivos ante el surgimiento de la protesta obrera, 1962-1976

\title{
Patronos, jerarcas y franquistas Actitudes y recursos coercitivos ante el surgimiento de la protesta obrera, 1962-1976
}

\author{
Masters, hierarchs and francoists \\ Attitudes and coercive resources before the emergence of the \\ workers' protest, 1962-1976
}

\author{
Cristian Ferrer González \\ Universitat Autònoma de Barcelona (España) \\ cristian.ferrer@uab.cat
}

\begin{abstract}
Resumen
Este artículo explorará la relación entre el surgimiento de la protesta obrera y el desarrollo de nuevos recursos para su contención y neutralización durante la segunda mitad del régimen de Franco. Focalizará en el caso de Tarragona, una ciudad catalana de industrialización reciente que hasta finales del franquismo figuró entre las provincias menos movilizadas de España. La ausencia de tradición contestataria, la falta de experiencia en el trabajo industrial o la memoria de la violencia fundacional del franquismo, fueron algunos de los elementos que condicionaron la aparición del movimiento obrero antes de la década de 1970. Incluso tras el acelerado proceso de industrialización de los años sesenta, el orden laboral y político permaneció bajo control de las autoridades y el surgimiento de la protesta socio-laboral se encontró frente a unas autoridades poco avezadas a combatirlo. El debilitamiento de los mecanismos de disciplinación laboral por parte del movimiento obrero y la impericia de las fuerzas policiales par descabezar las organizaciones que sostenían la protesta, propició el desarrollo de nuevas y diversificadas respuestas patronales, del sindicalismo oficial y de los apoyos sociales de la dictadura, que tras el desborde de la movilización tomarían caminos divergentes.
\end{abstract}

Palabras clave

movimiento obrero; violencia política: extrema derecha; antifranquismo.

\begin{abstract}
This article will explore the relationship between the emergence of the workers' protest and the development of new resources for containment and neutralization during the second half of Franco's regime. It will focus on the case of Tarragona, a Catalan city of recent industrialization that until the end of Franco was among the least mobilized provinces in Spain. The absence of a rebellious tradition, the lack of experience in industrial work or the memory of the foundational violence of Franco, were some of the elements that conditioned the emergence of the labor movement before the 1970s. Even after the accelerated industrialization process in the sixties, the labor and political order remained under the control of the authorities and the emergence of the socio-labor protest was faced with a few experienced authorities to fight it. The weakening of the mechanisms of labor discipline by
\end{abstract}

Esta obra está sujeta a la Licencia Reconocimiento-NoComercial-CompartirIgual 4.0 Internacional de Creative Commons. http://creativecommons.org/licenses/by-nc-sa/4.0/ 


\section{Cristian Ferrer González}

the labor movement and the inability of the police forces to break up the organizations that supported the protest, led to the development of new and diversified employer responses, official unionism and social support of the dictatorship, that after the overflow of the mobilization would take divergent paths.

\section{Keywords}

labor movement; political violence; extreme right; anti-Francoism

\section{Una dictadura de clase}

La dictadura franquista nació como alternativa a la apertura democrática que significó la Segunda República española. Desde un punto de vista social, los años treinta habían establecido en España el marco propicio para que el movimiento sindical planteara sus propuestas sociales y políticas, que la confabulación derechista vencedora en la Guerra Civil consideraba necesario extirpar de raíz. Desde esta perspectiva, el nuevo régimen se erigió en el garante de una «paz social» sustentada en la negación de los antagonismos de clase - subsumidos en la empresa común nacional-sindicalista - que, a la sazón, hacía necesaria la erradicación física, material y cultural del obrerismo. Cataluña había sido des de la segunda mitad del siglo XIX la región más industrializada de España, todavía reuniendo a inicios de la década de 1970 más del 20\% del global industrial español (Riquer, 2010, 815). Mayoritariamente, la industria catalana se concentraba en los entornos de Barcelona, conformados por medianas ciudades que se extendían a lo largo de su cinturón industrial en un radio de unos 60 kilómetros (Balfour, 1994); un espacio que aglutinaban a esas alturas el 68\% del empleo fabril catalán (Rodríguez \& D’AlósMoner, 1978).

El control social sobre Barcelona y su entorno, una región de gran importancia para el movimiento obrero español y que el régimen siempre la identificó como potencialmente desafecta, demandó el empleo de un gran número de recursos represivos a lo largo de la dictadura. Pero no sólo allá. La violencia constituyente del proyecto de construcción del Nuevo Estado - lo que Paul Preston $(2011,615)$ ha llamado la «inversión en terror» del franquismo- se mostró en entornos mucho menos conflictivos que la ciudad de Barcelona. Tarragona, una pequeña capital provincial de apenas 40.000 habitantes en los años treinta, da muestra del carácter clasista de la represión de postguerra: hasta el 52\% de los represaliados de dicha ciudad eran trabajadores industriales o agrícolas y de ese mismo grupo social eran el 80\% del total de ejecutados (Solé Sabaté, 1985; Recasens, 2005).

La represión bajo el franquismo, aunque masiva, fue siempre selectiva. Más allá del límite económico que aconsejaba salvaguardar manos para trabajar, la violencia fundante del franquismo perseguía un fin político: socializar el terror en el seno de las clases trabajadoras y, más extensamente, entre las bases de apoyo del proyecto republicano. Este hecho, junto al sistema de delaciones ciudadanas que pretendía 


\section{Patronos, jerarcas y franquistas. Actitudes y recursos coercitivos ante el surgimiento de la protesta obrera, 1962-1976}

crear nuevas redes de apoyo a la dictadura, aspiraba, en última instancia, a destruir las formas en que se relacionaban los sectores populares e inhabilitarles, así, para confiar los unos en los otros; un elemento, el de la confianza, imprescindible para relacionarse, solidarizarse y, eventualmente, organizarse (Mir, 2002; Sánchez Mosquera, 2008; Gómez \& Marco, 2011). Y aunque ningún régimen político sobrevive cuatro décadas sin construir mínimas bolsas de consentimiento, los estudios llevados a cabo al respeto dan muestra de lo limitado de dichas pretensiones (Molinero, 2004; Lanero, 2013). Asunto distinto son la amplia gama de actitudes adaptativas registradas entre las clases populares, que asumieron la dictadura como un hecho consumado, y que mayoritariamente carecían de recursos organizativos para oponerse a ella (Hernández Burgos, 2013).

La represión consiguió acabar con la organización obrera, pero no con las causas que habían propiciado su surgimiento. Las primeras muestras de malestar laboral bajo el franquismo en Cataluña se registraron en Barcelona y su cinturón industrial — debido a la protección que ofrecía el medio con respeto a ciudades de menor tamaño-y, particularmente, entre los sectores de mayor tradición sindical, como el textil o la metalurgia. La huelga había sido tipificada como delito punible por la legislación dictatorial, por lo que el «rechazo pasivo» (Ysàs, 2008, 170) del proletariado se expresó en paros cortos, trabajo lento o, incluso, en pequeños hurtos y absentismo laboral. Aunque se produjeron estallidos de protesta obrera en forma de huelga general en municipios del primer y segundo cinturón barcelonés en los años cuarenta, el surgimiento de una conflictividad organizada y sostenida en el tiempo no cabe buscarla antes de la década de 1960.

La huelga general de 1951 en Barcelona —la llamada «huelga de los tranvías»mostró, al menos, dos cosas: la incapacidad del franquismo para desactivar el conflicto social en los espacios urbanos, por un lado, y que entre las clases populares había muchos sectores dispuestos a movilizarse pese a los riesgos que comportaba, por el otro. Junto a la sempiterna represión y ante lo limitado de las políticas asistenciales, el régimen pretendió apagar las protestas laborales cada vez más frecuentes de la década de 1950 mediante el decreto de incrementos salariales generalizados, que beneficiaban tanto a los sectores movilizados como a lo que no. Pero si ello permitió la recuperación general de los niveles retributivos anteriores a la Guerra Civil, estos también contribuyeron a una inflación galopante que, a su vez, motivó nuevas protestas. Los pactos ofrecidos por los patronos a sus trabajadores al margen de los canales oficiales buscaban evitar los paros laborales, pero su proliferación produjo la erosión de los mecanismos de disciplinamiento laboral del primer franquismo. La introducción de los convenios colectivos respondía a las exigencias del proceso de liberalización económica, pero a su vez, tuvieron efecto sobre la morfología de la acción colectiva. ${ }^{1}$ Si por un lado estos permitían vincular los salarios a la productividad y acabar con una inflación congénita, por otra,

\footnotetext{
${ }^{1}$ Ley sobre convenios colectivos sindicales, Boletín Oficial del Estado, núm. 99, 25 de abril de 1958. Aunque la ley fuera de 1958, hasta después de 1962 los convenios no empezaron a introducirse extensivamente.
} 


\section{Cristian Ferrer González}

segmentaban a nivel de fábrica o de ramo los conflictos que anteriormente se habían planteado a nivel local, comarcal y, al fin, en grandes oleadas que forzaban al gobierno a conceder incrementos generalizados (Balfour, 1994; Domènech, 2008). Y al hacer eso, también rompieron el mecanismo que permitía las mejoras salariales de forma «pasiva» fuera de los principales centros fabriles, creando las condiciones, o al menos la necesidad, para la movilización laboral en aquellos entornos hasta la fecha no movilizados.

En 1962 una masiva oleada huelguística agitó los cimientos de la España industrial, expandiéndose desde Asturias hacia toda la geografía peninsular (Vega, 2002). En Cataluña, las protestas llegaron a través de la región minera de las comarcas interiores de Barcelona, y alcanzaron poco después la capital provincial, desde donde la protesta se extendió, como en precedentes ocasiones, por su primer y segundo cinturón. Aunque aquella oleada tuvo repercusiones tan alejadas de las principales urbes del país - como las minas del Mequinenza, entre el limes provincial entre Lleida y Zaragoza, así como en algunas industrias de Girona y entre los trabajadores de limpieza municipales de Lleida capital - lo cierto es que en la mayor parte del territorio catalán apenas llegaron ecos audibles de la agitación obrera que se estaba produciendo en la España industrial. ${ }^{2}$

El Gobierno Civil de Tarragona podría haber zanjado sin más el informe requerido por el ministro de la Gobernación, aduciendo que nada digno de mención había sucedido durante la oleada huelguística en la provincia. Sin embargo, las autoridades constataron que bajo una calma sólo aparente se dieron actitudes expectantes de cuánto estaba sucediendo en otros lugares más movilizados. El informe reconocía que el «desarrollo de los pasados sucesos, ha sido observado con un relativo interés» por los obreros, que «merecen especial atención por sus reacciones y actitudes». Este interés había motivado que muchos asalariados, procurando sortear la férrea censura, hubiesen sintonizado emisoras extranjeras principalmente radio Pirenaica, la estación de difusión de los comunistas españoles que emitía en onda corta desde Rumanía- que fueron «escuchadas por una gran mayoría de personas y las noticias eran rápidamente conocidas» por ser, aquella, «una situación nueva, desconocida y olvidada ya por muchos». ${ }^{3}$ Pero la pasiva expectación obrera no se redujo a la escucha de emisoras prohibidas. Algunos ferroviarios y estibadores, que eran los sectores de mayor tradición obrera de la ciudad, confeccionaron octavillas llamando a la huelga y las esparcieron por la zona portuaria. Y aunque fueron desoídas, este hecho nos habla de la presencia - de una presencia débil, si se quiere- de todo un mundo anterior que el franquismo no fue

\footnotetext{
2 Informe sobre el impacto de las huelgas de Asturias en las cuencas mineras de Lleida, 5 de julio de 1962, Archivo Histórico Provincial de Lleida, Fondo del Gobierno Civil, caja 1777; «Memoria de Gestión de Gobiernos Civiles del año 1962», 1963, Archivo General de la Administración (AGA), Fondo de Gobernación, Tarragona, caja 44, leg. 11331; «Informe del Comitè Executiu al IV Ple del Comitè Central», enero de 1963, Archivo Nacional de Cataluña (ANC), Fondo del Partido Socialista Unificado de Cataluña (PSUC), núm. 41, carpeta 4.

${ }^{3}$ Informe sobre la situación provincial ante las huelgas de 1962, 12 de julio de 1962, Archivo Histórico Provincial de Tarragona (AHPT), Fondo del Gobierno Civil (GC), caja 4367.
} 


\section{Patronos, jerarcas y franquistas. Actitudes y recursos coercitivos ante el surgimiento de la protesta obrera, 1962-1976}

capaz de erradicar por completo y que, pese a todos los constreñimientos, miedos e incertidumbres, de algún modo seguía ahí.

\section{Disputa obrera, pactismo patronal y contención sindical}

Estos sectores tradicionales tendrían una incidencia modesta en el ciclo de conflictividad registrado a partir de 1970, del que se hablará más adelante, pero fueron los que dieron mayor muestra de resistir en los entornos laborales a la implementación de la nueva organización del trabajo de tipo «fordista» que traían con sigo los convenios colectivos en los años sesenta (Ferrer, 2018b). Una organización que no estaba basada tanto en la automatización de los procesos productivos como en la implantación de un modelo intensivo en trabajo, que era tan brutal, que hay investigadores que sostienen que sólo era posible en el contexto de una dictadura (Babiano, 1995; Domènech, 2012). La prolongación de jornadas laborales y el desequilibrio entre incrementos de la productividad y los salarios, son algunos datos que podrían traerse a colación para ilustrarlo (Molinero \& Ysàs, 1998).

Las resistencias a este sistema intensivo en trabajo en los espacios sin tradición contestataria como Tarragona, empezaron a registrar pequeños conflictos que rara vez quedaban reflejados en las estadísticas oficiales, cuya sistematización no se inició antes de 1966. El tipo de conflictividad laboral que en aquella década se produciría en los entornos cuya clase obrera carecía de recursos para la movilización era de «baja intensidad», equiparable, aunque no exactamente igual, a la de epicentros industriales de los años cuarenta. Generalmente, una parte de la plantilla disminuía el ritmo de trabajo ante la negativa de la empresa de cumplir alguna de sus demandas. Aunque la ley penara este tipo de prácticas, ${ }^{4}$ tal modelo de conflictividad permitía esquivar la represión —especialmente la policial- mejor que no otro más disruptivo. Igualmente, su carácter de protesta impulsada desde pequeños círculos, forzosamente basados en la confianza, establecía una base sólida desde la que más adelante podrían ir extendiéndose los desafíos. Sin duda, el hecho de que se mostrara un modelo exitoso, al lograr ir arrancando pequeñas mejoras laborales, también contribuyó a ello. En un contexto de crecientes movilizaciones de este tipo, la represión patronal contra individuos concretos - sanciones, suspensiones, despidos - podían desactivar la actitud desafiante de parte de la plantilla, especialmente en unos años en que todavía no existían formas organizadas de lucha en las fábricas ni un tradición de protesta que sirviera de aglutinante entre los asalariados.

\footnotetext{
${ }^{4}$ En el Fuero del Trabajo, la primera de las Leyes Fundamental del franquismo, establecía en su título noveno que «Los actos individuales o colectivos que de algún modo turben la normalidad de la producción o atenten contra ella, serán considerados como delitos de lesa patria», estableciendo igualmente que «La disminución dolosa del rendimiento en el trabajo habrá de ser objeto de sanción adecuada». Boletín Oficial del Estado, núm. 505, 10 de marzo de 1938.
} 


\section{Cristian Ferrer González}

Pero la actitud de los empresarios cambió a media que se fue desarrollando y extendido una cultura de la protesta entre crecientes segmentos de la clase obrera. Es decir, una cultura cimentada en la constatación de que sólo mediante la acción colectiva $-\mathrm{y}$ no las salidas individuales o aquellas ofrecidas por los jerarcas sindicales- podía esperarse cambiar la propia vida (Domènech, 2012, 201). Claro está que muchos trabajadores seguirían permaneciendo al margen de las reivindicaciones laborales, bien por el temor a sufrir represalias, bien por - como ha investigado Hernández Burgos $(2013,363)$ - estimar que convenía evitar los actos de protesta, «por formar parte del terreno de lo político». Y aunque las actitudes obreras fluctuarían a lo largo del tiempo, su relación con la represión patronal también lo haría. El recurso represivo ante el éxito continuado de las reivindicaciones obreras, podía propiciar la cohesión de la plantilla de una empresa, más que desincentivarla. Un buen ejemplo lo encontramos en una multinacional textil tarraconense, en la que las costureras de una ala de la fábrica llegaron a estar horas en pie sin confeccionar una sola camisa como queja por sus condiciones de trabajo. Cuando la dirección despidió a una de las alborotadoras, confiando que cundiría el ejemplo, el paro se extendió entre gran parte de las seiscientas trabajadoras en plantilla. Lograron, así, no sólo que se anulara el despido, sino también que se cumplieran sus reivindicaciones. ${ }^{5}$

Resulta significativo que los patronos no siempre notificaran estas actitudes desafiantes a las autoridades sindicales, cuya teórica función consistía en mediar y evitar los conflictos, ni tampoco a la fuerza pública, cuya actuación la reservaban para casos extremos de insumisión, que todavía no se habían producido. La inexperiencia patronal ante la contestación obrera era, sin duda, un factor explicativo. Pero a menudo el motivo era que el amplio repertorio de protesta fabril - desde negarse a comer en las cantinas de la empresa, a la entonación de canciones en tono de mofa con referencias a los capataces, pasando por la negativa a realizar horas extraordinarias, que al fin y al cabo eran voluntarias - difícilmente podía ser considerado un conflicto laboral en sentido estricto. No era inusual que los trabajadores elevaran sus demandas simultáneamente al sindicato vertical y a la dirección de la empresa, acompañando dicha actuación legal con medidas a-legales de presión de baja intensidad como las descritas. Lo relevante es que estas movilizaciones que llamamos «silenciosas» - en tanto que no eran abiertas y visibles más allá de los implicados - fueron consiguiendo pequeñas mejoras laborales y, más relevante en términos históricos, extendiéndose por otras empresas y dotando a las plantillas de la cohesión que les permitiría dar un salto desde las protestas de baja intensidad a las huelgas productivas.

Pero hay también un factor político vinculado a lo anterior que permite interpretar las actitudes patronales. Y es que el éxito de buena parte de las reivindicaciones laborales por parte de un movimiento obrero en fase formativa cabe comprenderlo

\footnotetext{
5 «Carta de'n Sitges», 29 de agosto de 1966, Archivo Histórico del Partido Comunista de España (AHPCE), Fondo Nacionalidades y Regiones (NR), Cataluña, caja 65, carpeta 3. «Trabajadoras de Seidensticker», CCOO de Tarragona, octubre de 1966, ANC, Fondo PSUC, núm. 1603, caja 130.
} 


\section{Patronos, jerarcas y franquistas. Actitudes y recursos coercitivos ante el surgimiento de la protesta obrera, 1962-1976}

desde un marco más amplio, caracterizado por el surgimiento de un nuevo instrumento de oposición al franquismo de base obrera que había irrumpido en las principales regiones industrializadas de España: las Comisiones Obreras (CCOO). Se trataba de un movimiento sociopolítico - no un sindicato sensu stricto- surgido como alternativa al agotamiento estratégico del ciclo de conflictividad laboral por oleada de 1956 a 1962 en las principales áreas industriales y que vehicularía el grueso de la protesta laboral durante el franquismo (Molinero \& Ysàs \& Tébar, 1994). Si con anterioridad las CCOO se formaban y desaparecían tras el conflicto, a partir de 1964 se vieron como un espacio que permitía tejer realidades fabriles, locales y regionales diversas, por lo que empezaron a organizarse como una estructura permanente. De 1964 a 1966 las CCOO en Cataluña eran una realidad estrictamente barcelonesa, pero entre 1966 y 1967, los comunistas del Partido Socialista Unificado de Cataluña (PSUC) y los cristianos de la Hermandad Obrera de Acción Católica (HOAC) - los dos grandes actores políticos del nuevo movimiento obrero bajo el franquismo- fomentaron su articulación territorial en la llamada Comisión Obrera Nacional de Cataluña (CONC).

La confianza de algunos sectores movilizados de la clase obrera ante los patronos y la actitud de éstos ante las protestas fue parejo al despliegue territorial de las CCOO. Su desarrollo desde 1966 se habían amparado en la participación obrera en el sindicato vertical que el propio franquismo había propiciado (Amaya, 2013), lo que favoreció su infiltración por opositores encuadrados en CCOO. Sin embargo, a primeros de 1967 el Tribunal Supremo sentenciaba la ilegalidad del movimiento al considerarlo «una filial del Partido Comunista de España tendente a la violenta disolución de la actual estructura del Estado español», ${ }^{6}$ por lo que su ulterior crecimiento tuvo que desarrollarse en la clandestinidad. El papel de CCOO en las protestas de baja intensidad en Tarragona fue subsidiario, como también lo fueron los opositores infiltrados en el sindicato vertical, siendo mayor su rol en movilizaciones sociales ajenas a las fábricas, como las manifestaciones que empezaron a proliferar en torno al primero de mayo, o en el nuevo ciclo de conflictividad laboral abierto en 1968.

Una movilización convocada por CCOO en toda España para octubre de 1967, sin embargo, vendría a alterar esta relación. La violenta disolución de la manifestación en Terrassa por parte de la policía, que dejó treinta y cuatro detenidos y dos heridos de bala, anticipaba el giro represivo contra CCOO en el área de Barcelona, donde la patronal aprovechó la doble represión judicial y policial para depurar plantillas reivindicativas, pretextando la situación de crisis por la que atravesaba la economía. La represión a la que fueron objeto las CCOO entre 1967 y 1969 produjo su repliegue organizativo y un sinfín de debates muy polarizados en torno a las posiciones que apostaban por seguir actuando a cara descubierta, como hasta entonces, o, contrariamente, por su clandestinización absoluta; debates que produjeron la

\footnotetext{
6 «Comisiones Obreras y Partido Comunista. Informe», febrero de 1967, AGA, Presidencia, Secretaría General del Movimiento, caja 18.820.
} 


\section{Cristian Ferrer González}

división del movimiento en múltiples organizaciones que se consideraban herederas de las primeras y por ende auténticas CCOO. Ello coincidió, paradójicamente, con una actitud de confianza por el naciente movimiento obrero tarraconense, que propició que CCOO virara de acciones callejeras de escasa entidad a reivindicaciones en el seno de las empresas, hecho que fortaleció su estructura organizativa sectorial. Ello cabe vincularlo, por un lado, a la ausencia represiva en su entorno, pero especialmente por el éxito obtenido por las demandas obreras en tiempo reciente. La extensión de protestas de baja intensidad generó el contexto proclive para que las CCOO empezara a arraigar en algunas factorías y, de ahí, se pudiera dar el salto hacia un nuevo modelo de conflictividad laboral más disruptivo. El proceso de rápida industrialización del área de Tarragona en los años sesenta se fundamentó en la química (Llop, 2002), formándose un entramado de empresas mutuamente dependientes que las hacía muy sensibles a la conflictividad laboral, donde un pequeño grupo de activistas en una sola empresa podía afectar a la producción química de toda la ciudad. Entre estos sectores sería donde las CCOO de Tarragona empezaron a arraigar en las fábricas y a plantear demandas laborales con el aval de muchos compañeros de trabajo, que a diferencia de las acciones previas, ahora empezaban a participar directamente en las asambleas de empresa impulsadas por los militantes de CCOO. Ello significaba que cualquier actuación podría empezar a contar con un mayor respaldo por parte de la plantilla y, potencialmente, se ampliaba la capacidad de acción de los trabajadores, al tiempo que los dirigentes obreros contaban con la seguridad que les confería la multitud de la asamblea.

La primera huelga productiva en el corazón de las industrias química tarraconenses a principios de 1968 significó el franqueamiento de un límite no antes cruzado: el paro abrupto de la producción. ${ }^{7}$ Ello elevaría a los trabajadores de aquella empresa a referentes del movimiento obrero tarraconense y sus recursos de protesta empezaron a ser imitados en otras plantas (Ferrer, 2018a). Y aunque aquel paro fue muy relevante en la maduración del movimiento obrero, para los fines de este artículo conviene resaltar el hecho de que dicha huelga se encontró con menor estupor por parte del sindicalismo vertical y de la patronal que los siguientes paros laborales. El motivo lo mostró el salto que, poco después, darían los trabajadores que estaban construyendo la que era la segunda central nuclear de España en una población cercana a Tarragona: la ocupación del espacio público. Y es que fue la relación entre la protesta obrera en la esfera productiva y las dinámicas de movilización en el espacio público — un ciclo iniciado no antes de 1969- lo que convencería tanto a la patronal como al sindicalismo oficial y a las autoridades civiles de la necesidad de cambiar su estrategia para desactivar la protesta obrera.

\footnotetext{
7 Treball, num. 295, marzo de 1968.
} 


\section{Patronos, jerarcas y franquistas. Actitudes y recursos coercitivos ante el surgimiento de la protesta obrera, 1962-1976}

\section{Resistencia y la reacción patronal ante la ofensiva obrera}

La huelga en la construcción de la central nuclear Vandellós I empezó como tantas otras. El malestar por las condiciones de trabajo llevó a un grupo de activistas - ya organizados en CCOO- a proponer reuniones vespertinas en espacios seguros, alejados de los tajos y de la mirada patronal, con el fin de confeccionar una plataforma reivindicativa que superara la atomización del millar largo de trabajadores encuadrados en una veintena de empresas que realizaban labores en las obras de la central. Cuando presentaron sus demandas, los patronos se negaron a acatarlas. Pequeños grupos empezaron entonces a recorrer los tajos, invitando a sus compañeros a dejar de trabajar. Como factor de presión, decidieron reunirse en las cantinas que había instaladas cerca de las obras, en lo que al final del día se convirtió en un encierro de varios centenares de huelguistas. A diferencia de otras ocasiones, los patronos solicitaron la presencia de la Guardia Civil, que desalojó a los huelguistas tras cinco días de encierro. ${ }^{8}$ La construcción de la central era estratégica para el régimen franquista (Campubrí, 2017) y no parecían dispuestos a dejar amedrentarse por las reivindicaciones de unos trabajadores precariamente organizados. El hecho relevante es que la intervención policial -la primera que tengo registrada en estas latitudes - propició que la protesta se trasladara, por primera vez, del lugar de trabajo a las barriadas obreras de Tarragona, donde la mayoría de los huelguistas residían y donde la propia huelga se había fraguado. La huelga encontró ahí la solidaridad de otros trabajadores, que participaron en las movilizaciones callejeras, pese a ser en principio ajenos a sus motivaciones.

La dimensión extra-laboral que tomó el conflicto — con asambleas diarias en las iglesias y concentraciones de centenares de personas ante el sindicato vertical, en el corazón de la ciudad - tensionó las relaciones entre las autoridades civiles, garantes del orden público transgredido por la huelga, y la patronal de la construcción. Tras diversas manifestaciones en el centro de Tarragona, las primeras que se producían masivamente durante la dictadura, las autoridades enviaron a la Policía Armada a dispersarlas, pese a la intermediación de José Romero, uno de los líderes de la huelga. La violencia policial fue in crescendo a medida que avanzaba el tiempo, hasta que en el décimo día de huelga el Gobernador Civil ordenó desalojar una asamblea en una iglesia de barrio y detener a Romero. ${ }^{9}$ La policía custodió al detenido ante representantes de la patronal, donde se le obligó a aceptar la vuelta al trabajo. Pese a la cerrazón patronal, las manifiestas irregularidades por las que protestaban los trabajadores -que contravenían el convenio provincial (Heras, 1991, 51)— dejaban poco margen a los empresarios de la construcción. Éstos, a cambio de que

\footnotetext{
${ }^{8}$ La Vanguardia Española, 29 de agosto de 1969.

9 J.A. Serrano Montalvo había sido designado Gobernador Civil de Tarragona tras la huelga en la química de 1968, coincidiendo con el estallido de un escándalo de corrupción que afectaba a su predecesor y a varios cargos del ayuntamiento de Tarragona, incluido el alcalde. Hombre formado en las filas del falangismo universitario, sus métodos se mostraron mucho más agresivos e intransigentes con el movimiento obrero que los de su predecesor, si bien no puede afirmarse que su nombramiento guarde relación con el auge de la protesta laboral.
} 


\section{Cristian Ferrer González}

se les garantizara la hegemonía en la organización laboras en sus obras, accedieron a las demandas de tipo salarial. Las autoridades acallaban, así, la protesta en la calle, pero resultaba evidente que cabía evitar el desborde de las reivindicaciones laborales y para ello era imprescindible acabar con las CCOO.

La primera huelga «abierta» registrada en Tarragona fue considerada un éxito sin paliativos por el movimiento obrero, y no sólo en términos laborales. Era la primera ocasión que un conflicto obrero enturbiaba el orden público en aquellas latitudes; un orden público del que el franquismo era garante como defensor de la «paz social». Las reacciones de los patronos y de las autoridades - que mostraron su división de pareceres de manera pública- oscilaron entre la negociación y la represión. Pero finalmente, ante la constatación que el paro no era un conflicto aislado en unas pocas empresas alejada de la ciudad, sino una protesta sostenida por muchas personas en principio ajenas a ella, las autoridades consideraron que la primera de las opciones era necesaria para acabar con la huelga.

Ciertamente, fue una negociación totalmente condicionara por la actitud beligerante de las fuerzas policiales y la patronal. Muestra de ello es que algunos meses después, el conflicto en Vandellós I rebrotaría. ${ }^{10}$ Pero los nuevos métodos del movimiento obrero en Tarragona -asambleas, paro productivo y ocupación del espacio público- habían venido para quedarse, como también lo habían hecho la contundencia de la patronal y de las fuerzas del orden. Y si por primera vez la protesta era abierta y visible, también lo era su represión. Ello empezó a condicionar los debates estratégicos en el seno de las CCOO de Tarragona, como lo había hecho en Barcelona durante el trienio 1967-1969. Si hasta entonces la represión había afectado de una manera extensa al movimiento obrero en la primera y segunda corona barcelonesa, en el resto del territorio los golpes de la dictadura contra los opositores habían sido selectivos, buscando descabezar el movimiento antifranquista y esperando desmovilizar a sus bases con la amenaza de la coacción. Incluso tras el Estado de Excepción decretado en enero de 1969, que comportó numerosos arrestos por todo el territorio. ${ }^{11}$

1969 supuso un punto de inflexión en muchos sentidos. Desde entonces, la conflictividad socio-laboral comenzó a expandirse geográficamente lo suficiente como para que en 1970 el número de trabajadores de provincias españolas donde casi no se habían producido protestas anteriormente superasen a las tradicionalmente más conflictivas. ${ }^{12}$ En efecto, a la concentración de los recursos represivos en las provincias más conflictivas, le siguió la expansión de conflictos en

\footnotetext{
10 Treball, núm. 317, marzo de 1970.

11 El Estado de Excepción afectó a los artículos 12, 14, 15, 16 y 18 del Fuero de los Españoles, tercera Ley Fundamental del franquismo, por lo que quedaba en suspensión la libre fijación del domicilio, su inviolabilidad y se alargaba sine die la detención preventiva. La policía contabilizó más de 1.200 detenciones hasta primeros de abril en el conjunto español. Vid. «Consecuencias políticas de la suspensión del artículo 18 del Fuero de los Españoles», 12 de abril de 1969, AGA, Fondo Cultura, Ministerio de Información y Turismo (MIT), caja 671.

12 «Informe sobre conflictos colectivos de trabajo, 1970», 1971, Ministerio de Trabajo del Gobierno de España. Archivo Central del Ministerio de Trabajo (ACMT).
} 


\section{Patronos, jerarcas y franquistas. Actitudes y recursos coercitivos ante el surgimiento de la protesta obrera, 1962-1976}

otras. Las autoridades y los patronos se veían desbordadas y pedían más represión para contener y desactivar las protestas, pero la policía no podía más que constatar que ya no le era posible detener a nadie más, pues, tras la manga ancha que habían tenido durante el Estado de Excepción vigente de enero a marzo de 1969, ya no sabían a quien más detener. Este hecho nos habla de un relieve militante superior a la capacidad del franquismo para descabezar a los movimientos de protesta $y$, al mismo tiempo, que el antifranquismo, que había madurado un nuevo modelo de conflictividad que justo empezaba a brollar entonces, ya no era un fenómeno geográficamente reducido a unos pocos lugares.

La patronal, que con anterioridad había optado por la negociación - fuera directamente con los trabajadores o, más a menudo, a través del sindicato verticalpara desactivar los conflictos, reaccionó haciendo uso de los resortes de poder del estado, cuya principal atribución al fin y al cabo era garantizar su hegemonía en la esfera laboral. A corto plazo, la violencia policial contra el movimiento obrero logró su objetivo, con la atomización de las organizaciones de los trabajadores. En agosto de 1970 la policía sobrepasó un límite no antes franjeado, que tendría consecuencias permanentes en el movimiento obrero tarraconense: la tortura de diversos detenidos en una movilización en solidaridad por la muerte de tres obreros en Granada en el contexto de una huelga del sector de la construcción (Tudela, 2010). ${ }^{13}$ De hecho, hubo menos detenciones en 1970 que en 1969 y en 1971 (Tabla 1), pero el maltrato extremo de los detenidos condicionó a muchos de los trabajadores que se habían mostrado dispuestos a movilizarse, reactivando lo que Sánchez Mosquera (2008) ha llamado el «miedo genético». A la tortura se le sumó la condena a dos y tres años de cárcel a dos militantes católicos de CCOO.

Desde entonces, las CCOO no representarían ya la única opción sindical de la oposición, pues una parte de la Juventud Obrera Católica (JOC) las abandonaron por desavenencias estratégicas con los comunistas y los católicos más veteranos. Paradójicamente, la división del movimiento obrero acabaría propiciando un incremento espectacular de la conflictividad laboral a partir de 1973, cuando se consolidaran las nuevas opciones sindicales de raíz católica, que se ubicaban en la órbita de la extrema izquierda, como el Topo Obrero o, más relevante, las Plataformas Anticapitalistas (Arnabat, 2012; Sans, 2017). Al auge de la protesta obrera le siguió un endurecimiento de las posiciones de la patronal, que empezaron a hacer uso de nuevos recursos coercitivos.

En efecto, el desalojo de los huelguistas por parte de la policía, algo inédito antes de 1969, pasó a estar al orden del día desde entonces. Sin embargo, pronto se comprobó que con ello no bastaba para amedrentar las protestas. La sensación de fortaleza por parte de las organizaciones obreras se tradujo en la expansión de la conflictividad

\footnotetext{
13 «Carta de Serós», 25 de agosto de 1970, AHPCE, NR, Cataluña, caja 59, carpeta 2; «Informe (Tarragona)», s.f. [septiembre de 1970], AHPCE, NR, Cataluña, caja 63, carpeta 16; Entrevista a José Arjona Luque, 2001 Archivo Histórico de la Comisión Obrera Nacional de Cataluña (AHCONC), Colección de Biografía Obreras. Véase Ferrer (2018a).
} 


\section{Cristian Ferrer González}

entre otras empresas menores. ${ }^{14}$ Los informes del sindicato vertical dejan constancia de este aumento de conflictos en 1973, que se «han dejado sentir a finales del año».15 Para hacerles frente, la patronal combinó los desalojos con los despidos de los activistas más significados y, des de principios de 1974, empezó a hacer uso de nuevos métodos de carácter ofensivo: los cierres patronales. El lockout, como medida de presión excepcional, perseguía tensionar la unidad de los trabajadores durante el conflicto, evitar la ocupación cada vez más frecuentes de las fábricas y recuperar la iniciativa en la esfera laboral.

Estos métodos más disruptivos por parte de los patronos y de la policía, lejos de amedrentar la protesta, motivaban la solidaridad de otras personas, que empezaban a ir más allá de la clase obrera. Ello se aprecia nítidamente en una carta enviada por el párroco de una barriada periférica — donde se habían producido un seguido de huelgas y violentas actuaciones policiales - al Gobernador Civil, en el que le decía: «Lo que ciertamente me ha dejado perplejo es que la policía ... tomase una postura, no de poner orden sino de sembrar el desconcierto entre los trabajadores. Creo que sinceramente fue esto lo que consiguió la policía con 7 jeeps, dos autocares y varios coches particulares de la policía con cascos, fusil en mano ... Ahora la mayoría de los obreros no dudan a favor de quién se halla la fuerza pública». ${ }^{16}$

Un factor que explica este incremento paralelo de la violencia policial y de los conflictos obreros es el debilitamiento del sindicalismo vertical. Con anterioridad, el vertical había sido un instrumento útil para los patronos y las autoridades, al lograr canalizar el descontento obrero hacia cauces legales y, por lo tanto, más o menos controlables. Su eficacia decayó a partir de las elecciones de 1971, que se saldaron con una infiltración notable de opositores en los ramos más movilizados. ${ }^{17}$ Igualmente, con la proliferación de alternativas organizativas a CCOO, que a menudo rechazaban la infiltración en los sindicatos franquistas como principio, particularmente Plataformas Anticapitalistas, se hizo más difícil la negociación entre huelguistas y empresarios en su seno para poner fin a los conflictos. Allá donde no bastaba con los instrumentos de coerción del régimen, pues, empezaron a llegar los apoyos sociales más radicalizados del franquismo. En efecto, a partir del debilitamiento de los medios de control social y del raquitismo de la hegemonía del régimen en determinados espacios que servían para amplificar las protestas laborales, como la universidad - que entonces comenzaba su «extensión» en las provincias con la apertura de las delegaciones universitarias en Lleida, Girona y

\footnotetext{
14 «Informe mensual», Organización Sindical Española (OSE) de Tarragona, junio y julio de 1973, AHPT, Fondo Central Nacional de Sindicatos (CNS), caja 341-B.

15 «Memoria 1973», copia fechada el 3 de enero de 1975, AHPT, CNS, caja 11.

${ }^{16}$ Carta del párroco de La Floresta (Tarragona) al Gobernador Civil, 10 de febrero de 1974, AHPT, Fondo Federación de Asociaciones Vecinales de Tarragona, caja 5, carpeta 5/1.

${ }^{17}$ Tras las elecciones sindicales de 1966, que sirvieron para que CCOO desarrollara su estructura tanto sectorial como territorial, el gobierno anuló las previstas para 1969. Las de 1971 solamente renovaron la mitad de los cargos. Pero en espacios donde la infiltración había sido minoritaria en 1966, como en Tarragona, aquellas elecciones parciales significaron un avance notable en la presencia de antifranquistas en los ámbitos inferiores del sindicato vertical, particularmente en la química y la construcción, donde en 1972 se formó una coordinadora inter-ramos (Ferrer, 2018a).
} 


\section{Patronos, jerarcas y franquistas. Actitudes y recursos coercitivos ante el surgimiento de la protesta obrera, 1962-1976}

Tarragona- o las barriadas obreras - con el surgimiento de un potente movimiento vecinal (Bordetas \& Sánchez, 2010) - se empezó a sentir la actuación de grupos de ultraderecha que decidieron pasar a la acción directa contra la oposición democrática «para llegar allí donde era imposible hacerlo por vías legales» (Casals, 1995, 77). Su desarrollo correría paralelo a la crisis del franquismo y, en Tarragona, maduraría en el bienio 1976-1977, pero podemos rastrar su presencia ocasional por lo menos desde 1970 y un incremento de sus acciones de 1973 en adelante. Este hecho nos habla del desgaste de algunos mecanismos de control social y de la erosión creciente de la hegemonía del régimen, que resultaría apabullante en los últimos años de vida de Franco.

\section{El desbordamiento sindical y la carta de la violencia}

Desde 1973 alguna cosa había cambiado en la composición social del antifranquismo. Se habían consolidado espacios de oposición que iban más allá del movimiento obrero, particularmente los movimientos vecinal y estudiantil. La mayoría de los detenidos en protestas callejeras en Tarragona seguían siendo trabajadores industriales, pero, junto a ellos, empezaron a aparecer estudiantes y profesionales liberales que se movilizaban junto a los obreros, fuera por cuestiones laborales, por reivindicaciones sociales para los barrios periféricos o en movilizaciones políticas en torno al Primero de Mayo o al 11 de Septiembre, diada nacional de Cataluña.

Detenciones conocidas y militancia atribuida por la policía

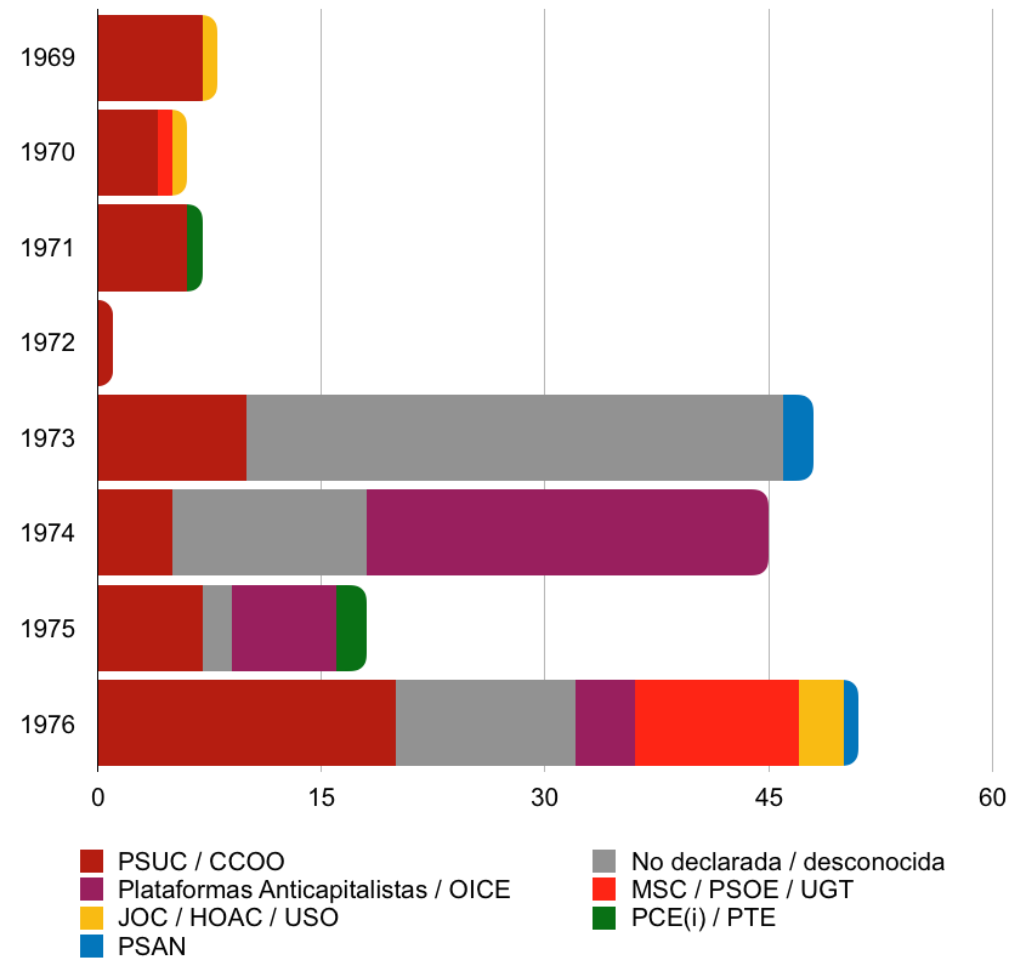

Tabla 1. Elaboración propia a partir de datos base de Heras (1991, 258-272). 


\section{Cristian Ferrer González}

La represión ya no se metabolizaba de la misma manera que pocos años atrás. Un abismo parecía separar 1973 de la disyuntiva de 1970, cuando la acción policial y la tortura de unos pocos detenidos provocó la división del movimiento obrero. En términos generales puede decirse que la represión empezó a volverse contraproducente para el régimen, pues a cada nuevo acto represivo le seguían movilizaciones anti-represivas que, a su vez, eran respondidas por el régimen con más represión. Ello no la hacía disminuir, pues de hecho se incrementó notablemente en los últimos años del franquismo (Tabla 1). Pero un análisis de los datos disponibles sobre su extracción da muestra de cuánto se había transformado la oposición en tan poco tiempo. Si hasta entonces los detenidos eran mayoritariamente personas conocidas por la policía y con una militancia concreta, aquel 1973 tomó cuerpo una nueva hornada de antifranquistas que participarían en las iniciativas de la oposición, pero que no siempre se encontrarían encuadrados en organizaciones formales, o cuya militancia era tan reciente que para la policía eran gente nueva y totalmente desconocida. Este fue uno de los factores que permitieron que el antifranquismo diese el salto hacia un movimiento de masas.

Los movimientos sociales — con el movimiento obrero a la cabeza- habían iniciado un tipo de acción pública y abierta que también transformó la represión del régimen, que pasó a ser también pública y abierta, pues ya nunca más recaía sobre militantes clandestinos y anónimos, sino sobre luchas que muchos conocía y de las que no menos se beneficiaban. El hecho que los represaliados no fueran anónimos sino gente conocida y respetada en sus barrios y empresas propició que la lucha contra la represión continuara siendo un punto de unidad mínima entre un antifranquismo cada vez más plural y que a menudo se encontraba en competencia entre sí. Pero los protagonistas ya no eran los partidos sino un nuevo tejido social capaz de establecer un continuum entre lucha política, social y cultural representado por la Asamblea de Cataluña, la primera plataforma unitaria de la oposición cuyos integrantes eran partidos, movimientos sociales, personalidades a título individual, así como asociaciones cívicas legales de todo tipo. El apoyo a los represaliados y, más extensamente, al antifranquismo por parte de las jerarquías eclesiásticas de la provincia, con el arzobispo a la cabeza, eran viva muestra de la cambiante relación entre la sociedad y un régimen crecientemente aislado y abandonado por el que había sido uno de sus apoyos fundamentales. ${ }^{18}$

La proliferación de protestas en los barrios obreros fueron respondidas con extrema dureza y en algunos casos — como durante un boicot a los autobuses en 1974, que prácticamente derivó en una huelga general de barrio- en la militarización de facto de la zona. Desde que se estrenara en el cargo en 1971, el Gobernador Civil Antonio Aigé Pascual empezó a utilizar de manera sistemática a las fuerzas del orden para desactivar las protestas laborales, vecinales y estudiantiles, produciéndose durante su mandato numerosos lockout patronales y el cierre de la universidad en diversas ocasiones. No era una situación excepcional de aquella pequeña ciudad de poco más

18 «Informe de Tarragona», 26 de noviembre de 1973, AHPCE, NR, Catalunya, jacq. 2526. 


\section{Patronos, jerarcas y franquistas. Actitudes y recursos coercitivos ante el surgimiento de la protesta obrera, 1962-1976}

de 100.000 habitantes. En 1974 prácticamente todas las provincias españolas presentaron alguna huelga laboral, mientras que diez años antes, las conflictivas no alcanzaban la decena. ${ }^{19}$

Fue en verano de aquel año que un conflicto laboral ubicó a la provincia de Tarragona como la segunda en horas no trabajadas a nivel español, sólo por detrás de Barcelona, pero por delante de Valencia, Vizcaya, Sevilla o Madrid. ${ }^{20}$ El motivo fue el conflicto que durante setenta días paralizó la producción en multinacional textil Valmeline - una de las mayores empresas de Tarragona, cuya plantilla era muy joven, mayoritariamente femenina y que en los años anteriores había dado muestras de tener una gran disponibilidad para la movilización- que contó con un apoyo muy extendido entre la población (Ferrer, 2017; Fuente, 2019). Aquella huelga, de hecho, inauguró una nueva fórmula de lucha antisindical, que fue la «batalla» por la opinión pública a través de la prensa provincial, que ya no desaparecería hasta el final del franquismo. En efecto, en las páginas del Diario Español, el portavoz provincial del partido único, se pudieron empezar a seguir los conflictos laborales. Lejos de su ocultación, como en tiempos precedentes, a partir de entonces los franquistas intentaron disputar el relato de las huelgas, destacando su daño económico, la aleatoriedad y caprichoso de sus reivindicaciones, su instrumentalización por parte del antifranquismo y, en particular, del comunismo, así como la coacción practicada por los piquetes contra los trabajadores «honrados» que solamente querían proveer a sus familias. Y es que, como reconociera el propio sindicato vertical reconocía en sus informes internos, «el conflicto de Valmeline SA ha polarizado la atención laboral de la provincia». ${ }^{21}$ La disputa por la opinión pública se explica por esta dimensión que cobró el conflicto y, especialmente, por el apoyo social que recibió - ya fuera en forma de ayuda económica o de huelgas en solidaridad.

El liderazgo de la huelga lo llevaron trabajadoras del Topo Obrero, que si bien no rechazaban la infiltración sindical como principio, asumían que la soberanía decisoria en las negociaciones dirección-plantilla debía residir en la asamblea de fábrica. Ni las autoridades ni la dirección de la empresa reconocían la legitimidad de la asamblea $a d h o c$, por lo que la resolución negociada al conflicto se presentó como muy compleja. La dirección de Valmeline no dudó en requerir la intervención policial, que desalojó la ocupación de la fábrica producida al inicio de la huelga, después sancionó y despidió a todas las huelguistas - cerca de 200 en los primeros días - para, finalmente, clausurar la fábrica por diversas jornadas. ${ }^{22}$ Pero nada sirvió para desalentar la huelga más dilatada que vivió Tarragona, y una de las más largas bajo el franquismo a nivel español. El presidente provincial del ramo textil que según informes internos se esperaba que actuara como «hombre bueno» de cara

\footnotetext{
19 «Informe sobre conflictos colectivos de trabajo», Ministerio de Trabajo del Gobierno de España, 1964 y 1974 , ACMT.

${ }^{20}$ Cambio 16, núm. 148, 16-22 de septiembre de 1974.

21 «Informe mensual», OSE de Tarragona, 19 de septiembre de 1974, AHPT, CNS, caja 342.

${ }^{22} A B C, 16$ de agosto de 1974.
} 


\section{Cristian Ferrer González}

a las obreras -23 y un procurador en Cortes llegaron a mediar directamente en el conflicto, sin lograr su resolución. ${ }^{24}$

Para las autoridades civiles, la huelga en Valmeline se había convertido en el principal problema de orden público de la provincia, tras dos meses de un conflicto que no parecía agotarse. Más bien al contrario, pues fluía la ayuda económica desde otras fábricas, se multiplicaban las huelgas en solidaridad y muchos ciudadanos mostraron su apoyo a las «batas rojas», como se las conocía, en nutridas manifestaciones frente al sindicato vertical. Este apoyo popular a la huelga, la cerrazón de la dirección de Valmeline y el temor que albergaban otros sectores de la patronal tarraconense, temerosas de un efecto contagio, precipitaron un actuación inédita por parte de los jerarcas sindicales: mintieron en sus alegaciones en favor de las huelguistas y en contra de la empresa ante la Magistratura de Trabajo, la cual obligó a las multinacional textil a readmitir a todas las despedidas y a que les fuera abonado el salario de los días no trabajados (Ferrer, 2017). Casos análogos en otros lugares de España hacen difícil concebir que las autoridades civiles no estuvieran al corriente de este tipo de actuaciones y no cabe descartar que fueran quienes lo precipitaran. ${ }^{25}$

Éxitos como aquellos aumentaron la confianza de las plantillas y dispararon el número de horas perdidas en Tarragona, ${ }^{26}$ pasando de unas 20.000 en 1974 a cerca de 250.000 el año siguiente; un salto que quedó empequeñecido cuando en 1976 el sindicato vertical contabilizara en más de 1.300 .000 las horas perdidas en conflictos laborales. ${ }^{27}$ El espectacular aumento de la conflictividad tenía su propio correlato en términos de mejoras salariales, pues durante el trienio 1974-1976 los sueldo crecieron, de media, tres veces más de lo que lo hizo la productividad, recortando a menudo la tasa de beneficios patronales (Domènech, 2012). En este contexto se celebraron las elecciones de 1975 a los sindicales verticales, que debían renovar la totalidad de cargos en cada uno de sus niveles. La mayor preparación y experiencia acumulada por parte de los antifranquistas, así como la posición defensiva de sectores de la patronal y la desorientación de los apoyos sociales del verticalismo, hizo que numerosos miembros de la oposición consiguieran posiciones muy relevantes en zonas dónde hasta entonces la infiltración había sido dificultosa y, por ello, reducida a unos pocos ramos. Con una participación provincial cercana al $90 \%$ y una renovación de los cargos superior a 9 de cada 10, la infiltración comunista en los niveles inferiores del sindicato vertical tarraconense fue más que notoria, llegando a obtener también diversas vocalía en los niveles superiores e, incluso, la

\footnotetext{
23 «Informe...», cit., 19 de septiembre de 1974, AHPT, CNS, caja 342.

24 Lluita, núm. 16, octubre de 1974.

25 Durante las huelgas de Vitoria de 1976 el comisario de la policía se ofreció a los trabajadores como mediador con la patronal a cambio de cesar en las alteraciones del orden público (Carnicero, $2009,54)$.

26 La dinámica se produjo en toda España, pasando las horas perdidas, según la organización sindical, de 18,2 millones en 1974 a 110 millones dos años después. Véase Molinero \& Ysàs (1998). 27 «Memoria de actividades», Secretariado de Asuntos Sociales de la OSE de Tarragona, años 19741976, AHPT, CNS, caja 352.
} 


\section{Patronos, jerarcas y franquistas. Actitudes y recursos coercitivos ante el surgimiento de la protesta obrera, 1962-1976}

presidencia de la Unión de Técnicos y Trabajadores provincial del sindicato de la construcción. En este sentido, la eficacia del sindicalismo vertical para desactivar los conflictos de clase se mostró muy limitada a partir de entonces. Informes internos constataban que la «actividad de un número de estos Enlaces Sindicales, se empezó prontamente a sentir ... En el ambiente sindical y laboral se ha empezado a percibir, propensión hacia el planteamiento de la huelga no regulada, tanto por motivos laborales como políticos».28

En el contexto abierto con la muerte de Franco en noviembre de 1975, CCOO y la católica Unión Sindical Obrera (USO) lanzaron un comunicado conjunto llamando a la huelga general de 24 horas para el 11 de diciembre. Junto a reivindicaciones económicas, el llamamiento expresaba la voluntad de romper con un régimen que intentaba perpetuarse más allá de la vida del dictador que le dio nombre. ${ }^{29}$ Sin embargo, y pese a la extensa movilización en otras regiones de España, los jerarcas sindicales tarraconenses la calificaron como «un fracaso» para la oposición. ${ }^{30}$ Demás, durante las manifestaciones poco concurridas, algunos jóvenes comunistas y maoístas fueron detenidos y puestos a disposición judicial, que decretó prisión preventiva. ${ }^{31}$ Sin embargo, la expectativa que abría la posibilidad de un cambio político venció a la incertidumbre y ya desde inicios de 1976 empezaron a producirse movilizaciones de distinta naturaleza, reivindicando la amnistía y las libertades democráticas. De nuevo, estas campañas fueron respondidas por la prensa oficial con extensos artículos difamando la idea de democracia sostenida por la oposición, pues consideraban la «democracia orgánica» del franquismo como la única y genuinamente española. ${ }^{32}$

\section{Movilización social y división en los apoyos al régimen}

La patronal daría muestra de una actitud cambiante ante la situación de creciente conflictividad socio-laboral y de la perspectiva que se abría con la muerte de Franco. Combinaría el recurso de la fuerza a través de la policía y la negociación con los huelguistas, aunque solamente cuando la primera opción había sido desbordada por la movilización. ${ }^{33}$ Ello se vio muy claramente durante la huelga general que vivió el sector de la construcción en Tarragona entre finales de enero y mediados de febrero de 1976, cuando algunos dirigentes patronales negociaron la vuelta al trabajo con uno de los promotores de la huelga y militante de CCOO, que fue encarcelado durante los disturbios, José Estrada. Aunque le quedara año y medio de vigencia, la huelga se amparó formalmente en la petición de un nuevo convenio; pero su

\footnotetext{
28 «Memoria de actividades, Secretariado de Asuntos Sociales de la OSE de Tarragona, 1975, AHPT, CNS, caja 352.

${ }^{29}$ Luchas Obreras, núm. 79, 30 de noviembre de 1975.

30 «Memoria mensual», OSE de Tarragona, 31 de diciembre de 1975, AHPT, CNS, caja 343.

31 «Informació», 22 de diciembre de 1975, ANC, PSUC, núm. 939, caja 54.

32 «Reflexión entre amnistía y crimen», Diario Español, 10 de febrero de 1976.

33 Ello la diferenciaría, por ejemplo, de la patronal alabesa, que se mostraría intransigente ante las reivindicaciones laborales (Carnicero, 2009).
} 


\section{Cristian Ferrer González}

motivación última fue claramente política, pues pretendía conectar con la situación de paro general en la comarca del Baix Llobregat, así como en lo que estaba sucediendo en otros lugares de España en aquella coyuntura clave (Ferrer, 2018c; Riera \& Botella, 1976).

Sin embargo, la negociación patronal tenía claros límites, pues poco podían hacer para cumplir las expectativas últimas de los segmentos de población movilizados; es decir, para dar satisfacción a las reivindicaciones de amnistía y libertades políticas. Además, el incumplimiento sistemático de los acuerdos alcanzados una vez restablecido el orden laboral, dio argumentos a un número nada despreciable de trabajadores - cerca de un 40\%, según votación celebrada en asamblea- ${ }^{34}$ para seguir presionando en movilizaciones callejeras, tal como reivindicaban las organizaciones de la izquierda radical y a las que el PSUC y CCOO, más partidarios de la concertación y de forzar una negociación política, se sumaron ante la evidencia de los hechos.

Por otro lado, las autoridades civiles de la provincia tampoco tenían en sus manos dar cumplimiento a las reivindicaciones últimas de las movilizaciones, pues dependían del gobierno y los planes de éste pasaban por un rígido control del orden público. En el contexto de 1976, a diferencia de anteriormente, no podían permitirse mediar en favor de la resolución negociada de unos conflictos con clara carga política: «No puede permitirse que fuerzas empeñadas en la destrucción de lo que hoy es España, declaren una guerra de desgaste en la que los perdedores sean los propios españoles». ${ }^{35}$ Incapaces de ofrecer otra salida a las protestas, se dedicaron a intentar contenerlas, aumentando la presión sobre los manifestantes. La violencia alcanzó un punto no antes visto en Tarragona, llegándose a desplegar fuerzas venidas de otras provincias y haciendo uso de recursos no antes utilizados, como «botes de humo y balas de goma». ${ }^{36}$ La respuesta de los manifestantes también incrementaron su contundencia, con el levantamiento de «barricadas mediante la utilización de automóviles y containers de recogida de basura»,37 para luego «con piedras, siguieron hostigando a la Policía Armada».38

El cenit de las movilizaciones llegaría a primeros de marzo, cuando se produjo una protesta espontánea al conocerse el asalto policial en una iglesia en Vitoria en el contexto de una huelga general, que dejó cinco muertos y numerosos heridos (Carnicero, 2009). Un manifestante fallecería por la acción policial durante aquella manifestación de duelo en Tarragona. La oposición criticó al gobierno de la monarquía por «precipitar una situación de violencia que justifique sus intentos

\footnotetext{
34 «El conflicto de la construcción en Tarragona quedó resuelto», Diario Español, 13 de febrero de 1976.

35 «Lo de Vitoria», Diario Español, 5 de marzo de 1976.

${ }^{36}$ Diario Español, 11 de febrero de 1976.

${ }^{37}$ Anexo de la nota de la agencia informativa Europa Press del 5 de marzo de 1976, AGA, MIT, caja 42, legajo 9112, carpeta 14.

38 Diario Español, 6 de marzo de 1976.
} 


\section{Patronos, jerarcas y franquistas. Actitudes y recursos coercitivos ante el surgimiento de la protesta obrera, 1962-1976}

antidemocráticos» y les acusaba de quererles «retornar a los tiempos del miedo».39 Las huelgas laborales disminuyeron notablemente tras los trágicos incidentes, si bien aumentaron el número de manifestaciones convocadas por la Asamblea de Cataluña en Tarragona. El grueso de las autoridades aceptaba — de forma entusiasta o no, más sincera o menos- la necesidad de acometer reformas del ordenamiento franquista, pero la directriz gubernamental era que ésta se hiciera sin sobresaltos y evitando que fuera la presión popular la que marcara la agenda política. La presión desde abajo y la imposibilidad de abrir válvulas de escape sin trasgredir las directrices gubernamentales, llevó a movimientos autónomos entre la clase política en los niveles locales y provinciales que daban la sensación de desbandada. En Tarragona, por ejemplo, un concejal municipal llevó una proposición al pleno para que el ayuntamiento de la ciudad se adhiriese a los puntos de la Asamblea de Cataluña, que fue aprobado por unanimidad. ${ }^{40}$

\section{Consideraciones finales}

Era evidente que la adhesión del ayuntamiento de Tarragona a los objetivos de la oposición era un movimiento destinado a calmar los ánimos sociales en un contexto de ostracismo de las autoridades franquistas y de una movilización que, pese a todo, seguía. Se trata de una muestra significativa a nivel micro de cómo la movilización social contribuyó al cambio político. La moción en favor de las libertades democráticas exacerbó los ánimos de los ultraderechistas y también del gobierno, que destituyó al gobernador Aigé Pascual por su permisividad con la votación. En su lugar se nombró a Agustín Castejón Roy, otro hombre forjado en el falangismo universitario y cuyo corto mandato se caracterizó por su connivencia con las bandas violentas de ultraderecha, que se dedicaban a amedrentar a la oposición y a imprimir propaganda falsa en su nombre para intentar deslegitimarla. Poco después de la caída del gobierno de Carlos Arias Navarro, en julio de 1976, Castejón sería sustituido por un nuevo Gobernador de carácter aperturista, lo que motivaría que miembros de ultraderecha trataran de incendiar el edificio del Gobierno Civil con el objetivo de inculparlo a los comunistas, de quienes se temía su legalización. ${ }^{41}$

Pese a lo limitado de estas actuaciones, eran viva muestra de la profunda crisis de hegemonía del régimen franquista, que se debía fundamentalmente al desgaste político producido por la movilización social. Una movilización que contribuyó a agudizar las contradicciones entre los sustentos del franquismo, particularmente entre una patronal posibilista ante las incertidumbres del nuevo contexto político, unas autoridades civiles atrapadas entre el inmovilismo gubernamental y la presión desde abajo y unos apoyos sociales muy radicalizados, que veían como el régimen que se había levantado cuatro décadas atrás, en la Guerra Civil, iba camino de

\footnotetext{
39 Llamamiento de la Asamblea de Cataluña en Tarragona, 7 de marzo de 1976, reproducido en Heras $(1991,160)$.

40 «El Ayuntamiento de Tarragona pide el Estatut de 1932», El Correo Catalán, 27 de marzo de 1976.

${ }^{41}$ El País, 10 de febrero de 1977.
} 


\section{Cristian Ferrer González}

desnaturalizarse. Enfrente, una oposición unida en sus objetivos mínimos y cuya capacidad por condicionar el devenir político no se limitó a unas pocas grandes ciudades españolas, sino que se extendió a entornos periféricos como Tarragona. La violencia del régimen durante largo tiempo tuvo capacidad para moldear las actitudes sociales, para condicionar los debates entre la oposición y para determinar sus modelos de organización. Pero no de manera permanente. En los últimos años del franquismo, fue la movilización social la que acabó condicionando las posiciones políticas de los apoyos a la dictadura, dejando a la patronal sin los instrumentos de contención sindical, aumentando la división de las autoridades civiles y aislando en posiciones marginales a la ultraderecha.

\section{Bibliografía}

Amaya, Á. (2013). El acelerón sindicalista. El aparato de propaganda de la Organización Sindical Española entre 1957 y 1969. Madrid: Centro de Estudios Políticos y Constitucionales.

Arnabat, R. (2012). El moviment obrer autogestionari i el Topo Obrero (1972-1982). En M. Loff y C. Molinero. Sociedades en cambio: España y Portugal en los años sesenta. Bellaterra: CEFID.

Balfour, S. (1994). La dictadura, los trabajadores y la ciudad. El movimiento obrero en el área metropolitana de Barcelona (1939-1988). Valencia: Alfons el Magnànim.

Bordetas, I. y Sánchez, A. (2010). El moviment veïnal en (la) transició, 1974-1979. En Molinero, C. e Ysàs, P. (coords.). Construint la ciutat democrática. El moviment veïnal entre el tardofranquisme i la transició. Barcelona: Icaria.

Campubrí, L. (2017). Los ingenieros de Franco. Ciencia, catolicismo y Guerra Fría en el Estado franquista. Barcelona: Crítica.

Casals, X. (1995). Neonazis en España. De las audiciones wagnerianas a los skinheads (1966-1995). Barcelona: Grijalbo.

Casanellas, P. (2014). Morir matando. El franquismo ante la práctica armada, 19681977. Madrid: Catarata.

Domènech, X. (2008). Clase obrera, antifranquismo y cambio político. Pequeños grandes cambios, 1956-1969. Madrid: Catarata. 


\section{Patronos, jerarcas y franquistas. Actitudes y recursos coercitivos ante el surgimiento de la protesta obrera, 1962-1976}

Domènech, X. (2012). Cambio político y movimiento obrero bajo el franquismo. Lucha de clases, dictadura y democracia (1939-1977). Barcelona: Icaria.

Ferrer, C. (2017). Las batas rojas de Valmeline (Tarragona, 1974). Trabajadoras, huelguistas y referentes del movimiento obrero. Historia del Presente (30), 125-142.

Ferrer, C. (2018a). Sota els peus del franquisme. Conflictivitat social i oposició política a Tarragona, 1956-1977. Tarragona: Arola.

Ferrer, C. (2018b). Solidaridades y cultura de la protesta. Una mirada desde las periferias de Catalunya en los años sesenta. En G. Román y J. A. Santana (coords.). Tiempo de dictadura. Experiencias cotidianas durante la guerra, el franquismo y la democracia. Granada: EUG.

Ferrer, C. (2018c). El pulso de 1976. Las movilizaciones de Tarragona en el contexto española. Segle XX (11), 91-118.

Fuente, Á. de la (2019). Una història de dones en lluita. La conflictivitat laboral en empreses tèxtils multinacionals (1961-1980). Tarragona: URV/Arola.

Gómez, G. y Marco, J. (2011). La obra del miedo. Violencia y sociedad en la España franquista, 1936-1950. Barcelona: Península.

Heras, P. (1991). La oposición al franquismo en las comarcas de Tarragona (19391977). Tarragona: Mèdol.

Hernández Burgos, C. (2013). Franquismo a ras de suelo. Zonas grises, apoyos sociales y actitudes durante la dictadura (1936-1976). Granada: EUG.

Lanero, D. (2013). Las «políticas sociales» del franquismo: las obras sindicales. En M. A. del Arco, et. al. No solo miedo. Actitudes políticas y opinión popular bajo la dictadura franquista (1936-1977). Granada: Comares.

Llop, J. (2002). La industrialització de Tarragona (1957-1971) i les seves circumstàncies. Tarragona: Arola.

Mir, C. (2002). La colaboración en la represión. En: J. Casanova (coord.). Morir, matar, sobrevivir. La violencia en la dictadura de Franco. Barcelona: Crítica.

Molinero, C. (2004). La captación de las masas. Política social y propaganda en el régimen franquista. Madrid: Cátedra. 


\section{Cristian Ferrer González}

Molinero, C. e Ysàs, P. (1998). Productores disciplinados y minorías subversivas. Clase obrera y conflictividad laboral en la España franquista. Madrid: Siglo XXI.

Molinero, C., Ysàs, P. y Tébar, J. (1994). Comisiones Obreras de Cataluña: de movimiento sociopolítico a confederación sindical. En D. Ruiz (coord.). Historia de Comisiones Obreras (1958-1988). Madrid: Siglo XXI.

Preston, P. (2011). El holocausto español. Odio y exterminio en la Guerra Civil y después. Barcelona: Debate.

Recasens, J. M. (2005). La repressió a Tarragona. Tarragona: CEHS.

Riera, I. y Botella, J. (1976). El Baix Llobregat. 15 años de luchas obreras. Barcelona: Blume.

Rodríguez, Á. y D’Alós-Moner, R. (1978). Economía y territorio en Catalunya. Los centros de graveda de población, industria y renta. Barcelona: Alba.

Sánchez Mosquera, M. (2008). Del miedo genético a la protesta. Memoria de los disidentes del franquismo. Sevilla: Fundación de Estudios Sindicales.

Sans, J. (2017). Militancia, vida y revolución en los años 70: la experiencia de la Organización de Izquierda Comunista (OIC). Bellaterra: UAB.

Solé Sabaté, J. M. (1985). La repressió franquista a Catalunya, 1938-1953. Barcelona: Edicions 62.

Tudela, E. (2010). Nuestro pan. La huelga del 70. Granada: Comares.

Vega, R. (coord.) (2002). Hay una luz en Asturias. Las huelgas de 1962 en Asturias. Gijón: Trea.

Ysàs, P. (2008). El movimiento obrero durante el franquismo. De la resistencia a la movilización (1940-1975). Cuadernos de Historia Contemporánea (30), 164-184.

Recibido: 20/08/2019

Evaluado: $11 / 10 / 2019$

Versión Final: 12/11/2019 